\title{
PRIMARY NON-HODGKIN'S LYMPHOMA OF THE COMMON BILE DUCT PRESENTING AS OBSTRUCTIVE JAUNDICE: A CASE REPORT
}

\author{
Gabriel CONSTANTINESCU ${ }^{1,2}$, Madalina ILIE ${ }^{1,2}$, Vasile SANDRU ${ }^{1}$, Alexandru CONSTANTINESCU ${ }^{1}$, \\ Ecaterina RINJA ${ }^{1}$, Oana PLOTOGEA ${ }^{1}$, Daniel BERCEANU ${ }^{1}$, RUXANDRA OPRITA ${ }^{1,2} \bowtie$ \\ ${ }^{1}$ Clinical Emergency Hospital of Bucharest, Gastroenterology Clinic, Bucharest, Romania \\ ${ }^{2}$ „Carol Davila“ University of Medicine and Pharmacy, Bucharest, Romania
}

Received 19 Sept 2018, Accepted 07 Nov 2018

https://doi.org/10.31688/ABMU.2018.53.4.21

\begin{abstract}
Introduction. Primary non-Hodgkin's lymphoma of the extrahepatic bile duct presenting as obstructive jaundice is an extremely rare disease.

Case presentation. We report a case of obstructive jaundice caused by primary non-Hodgkin's lymphoma of the common bile duct (CBD), in a 67-year-old male patient. Our patient showed clinical evidence of obstructive jaundice, and tomography revealed a dilated common bile duct with the suspicion of intra ductal lithiasis. Endoscopic retrograde cholangiopancreatography (ERCP) was performed, with efficient drainage and clinical resolution of the obstructive jaundice. One month later, the patient presented the same clinical signs of obstructive jaundice, only this time the ERCP revealed common bile duct distal stenosis. The next step was to perform an echoendoscopy (EUS), that visualized a homogeneous mass at the common bile duct distal level and cholangiocarcinoma was suspected. Fine needle aspiration (FNA) of the lesion obtained tissue fragments for histological examination. The diagnosis was diffuse B-cell type non-Hodgkin's lymphoma in the marginal area, and the patient was
\end{abstract}

\section{Résumé}

Lymphome non-Hodgkinien primaire des voies biliaires simulant un ictère par obstruction: présentation de cas

Introduction. Le lymphome primaire non-Hodgkinien des voies biliaires extra-hépatiques, qui se présente sous la forme d'un ictère par obstruction, est une maladie extrêmement rare.

Rapport du cas. Nous rapportons un cas d'ictère obstructif causé par un lymphome primitif non-Hodgkinien du canal biliaire principal chez un homme âgé de 67 ans. Notre patient a présenté des signes cliniques d'ictère obstructif et la tomographie a révélé un canal biliaire principal dilaté avec la suspicion de lithiase. Une cholangiopancréatographie rétrograde endoscopique (CPRE) a été réalisée avec un drainage efficace et une résolution clinique de la jaunisse obstructive. Un mois plus tard, le patient présentait les mêmes signes cliniques de jaunisse obstructive que cette fois-ci, la CPRE révélait une sténose distale du canal biliaire commun. L'étape suivante consistait en une écho-endoscopie (EUS) permettant de visualiser 
evaluated in the Oncology Department for chemotherapy.

Conclusions. It is very important to differentiate primary non-Hodgkin's lymphoma of the bile ducts from other causes of obstructive jaundice, as the treatment approach and prognosis are fundamentally different. Endoscopic ultrasound-guided fine-needle aspiration (EUS-FNA) is the definitive diagnosis technique, avoiding surgical interventions and the classic exploratory laparotomy.

Keywords: obstructive jaundice, non-Hodgkin's lymphoma, echoendoscopy. une masse homogène du niveau distal du canal biliaire commun et un cholangiocarcinome était soupçonné. Une aspiration à l'aiguille fine (FNA) de la lésion avec des fragments de tissu et un bloc cellulaire a été obtenue pour l'examen histologique. Le diagnostic pathologique était un lymphome non-Hodgkinien de type B à cellules $\mathrm{B}$ diffus dans la zone marginale et le patient était évalué dans le Département d'Oncologie pour la chimiothérapie.

Conclusions. Il est très important de différencier les lymphomes primitifs non-Hodgkiniens des voies biliaires des autres causes de jaunisse obstructive, car l'approche thérapeutique et le pronostic sont fondamentalement différents. L'aspiration à l'aiguille fine sous guidage endoscopique (EUS-FNA) est dans ce cas le diagnostic définitif évitant les interventions chirurgicales et la laparotomie exploratoire classique.

Mots-clés: jaunisse obstructive, lymphome non-Hodgkinien, écho-endoscopie.

without fluid. Computed tomography was performed, confirming the ultrasound findings and alleviating the suspicion of stones in the distal biliary tract. The patient was transferred to our clinic for further investigations and specialized treatment. An endoscopic retrograde cholangiopancreatography (ERCP) was subsequently performed. The common bile duct was $12 \mathrm{~mm}$, without intrahepatic bile ducts dilatation.

Efficient drainage was performed, by removing stones from the main biliary duct using the basket. Approximately one month after discharge, the patient presented with clinical evidence of obstructive jaundice. Laboratory findings included hepatic cholestasis with a total bilirubin of $5.52 \mathrm{mg} / \mathrm{dL}$, liver cytolysis and hypocholesterolemia. Residual lithiasis was suspected. Endoscopic retrograde cholangiopancreatography revealed common bile duct distal stenosis. 10 Fr and 8.5 Fr plastic stents were placed. Due to the stenotic malignant aspect, echoendoscopy (EUS) was performed the next day. A relatively well-defined non-homogeneous mass of 22/17 mm diameter was visualized at the common bile duct distal level (Figure 1). Fine needle aspiration was performed. Peripancreatic adenopathies with a maximum size of $22 \mathrm{~mm}$ were also observed. The microscopic examination revealed lymphoid tissue with small lymphocytes, rounded nucleus and low cytoplasm, rare medium to large lymphocytes, rare mitosis. Necrotic tissue was absent, as well as epithelial cells. Immunohistochemistry revealed small B cells, positive tumor proliferation, positive for CD20, negative for CD5 (T marker), Cyclin D1 (B marker of mantle lymphoma) and CD10 (germinal center marker). 


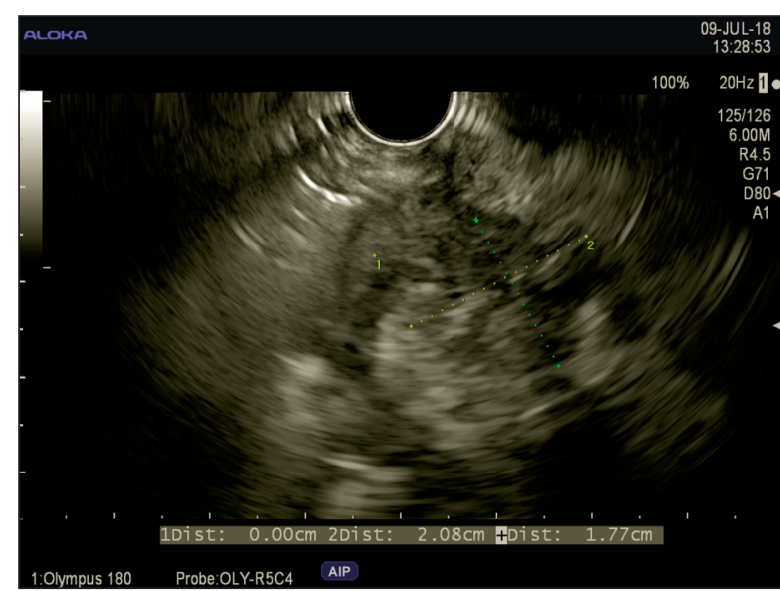

Figure 1. Non-homogeneous mass visualized by EUS at the common bile duct distal level

The Ki67 proliferation index was less than $10 \%$. The histopathological aspect and the immunohistochemical examination are compatible with non-Hodgkin malignant $\mathrm{B}$ cell in the marginal area. The last endoscopic retrograde cholangiopancreatography, one month after establishing the diagnosis of certainty, revealed distal stenosis over the last $2 \mathrm{~cm}$ (Figure 2). Two plastic stents of $10 \mathrm{Fr}$ were inserted with efficient drainage. After oncologic evaluation, combined chemotherapy including cyclophosphamide, doxorubicin, vincristine, and prednisone plus rituximab (CHOP-R) was started last month.

\section{Discussion}

Diffuse large B cell lymphoma is the most common lymphoid neoplasm and the most common histologic subtype of non-Hodgkin's lymphoma, accounting for approximately $25 \%$ of all cases ${ }^{3}$. The incidence increases with age, mostly over 60 years old, and the disease appears to be slightly more predominant in men (50\% of cases) than in women ${ }^{4}$. The gastrointestinal tract is the most common site of involvement with presenting symptoms such as abdominal pain, loss of appetite, weight loss and vomiting ${ }^{5}$. Obstructive jaundice is mostly secondary to compression of the extrahepatic bile ducts by periportal, perihepatic, or peripancreatic lymphadenopathy, associated tumor lysis, or direct hepatic involvement ${ }^{6}$. Although it remains unclear whether chemotherapy should precede the biliary drainage procedures in patients with non-Hodgkin's lymphoma presenting with jaundice, chemotherapy alone usually alleviates the obstructive jaundice without biliary drainage? Dudgeon et al described five patients with non-Hodgkin's lymphoma causing obstructive jaundice, who were treated with combined chemotherapy

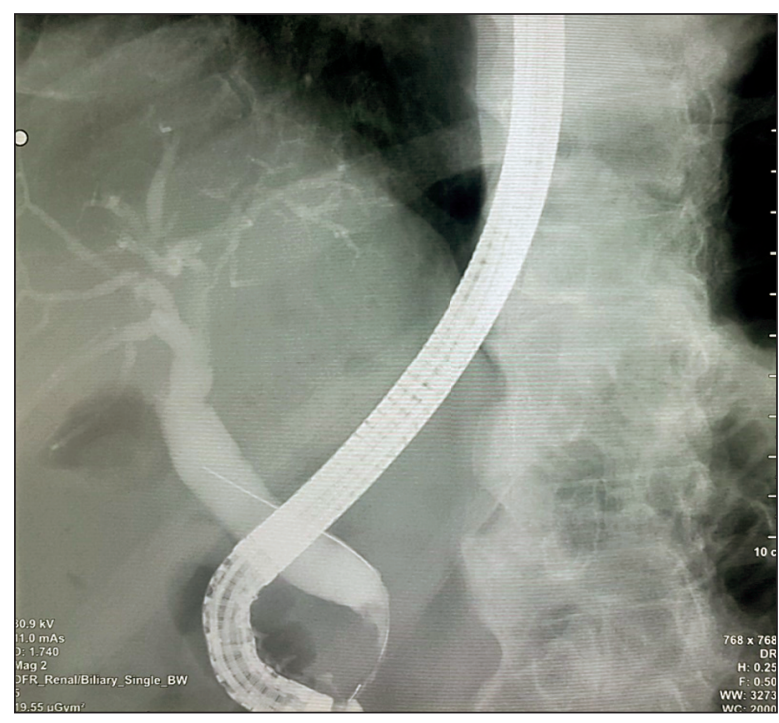

Figure 2. Common bile duct distal stenosis visualized at the endoscopic retrograde cholangiopancreatography

without prior surgical or endoscopic biliary decompression, or radiation therapy ${ }^{8}$. Fine needle aspiration (FNA) with endoscopic ultrasound (EUS) guidance is often required to direct therapy in the case of an uncertain diagnosis ${ }^{9}$. FNA with EUS guidance permits both morphologic and cytologic analysis of lesions at various locations such as within or adjacent to the gastrointestinal tract, and intra-abdominal and retroperitoneal masses ${ }^{10-15}$. EUS-FNA can have a role in diagnosing other lesions that may mimic cholangiocarcinoma and present either as a mass or with obstructive jaundice ${ }^{16-19}$. All reported cases indicate that common bile duct non-Hodgkin's lymphoma is a rapidly progressive disease and an accurate histopathologic diagnosis, fast treatment of other complications, in our case the obstructive jaundice, evaluation for surgical resection, if feasible, combined with chemotherapy with or without radiotherapy may be the approach to offer a chance for cure ${ }^{20}$.

\section{Conclusions}

It is very important to differentiate the primary non-Hodgkin's lymphoma of the bile ducts from other causes of obstructive jaundice, as the treatment approach and prognosis are fundamentally different. In our case, only after the second ERCP revealed a distal stenosis of the common bile duct, EUS was performed with the suspicion of cholangiocarcinoma. The tissue biopsy by EUS-FNA, with characteristic histopathologic and immunohistochemical findings, was the gold standard for definitive diagnosis. In conclusion, although primary non-Hodgkin's lymphoma of the biliary ducts is an extremely rare disease, it 
should be considered in the differential diagnosis of malignant obstructive jaundice.

\section{Compliance with Ethics Requirements:}

„The authors declare no conflict of interest regarding this article"

"The authors declare that all the procedures and experiments of this study respect the ethical standards in the Helsinki Declaration of 1975, as revised in 2008(5), as well as the national law. Informed consent was obtained from the patient included in the study"

"No funding for this study"

\section{References}

1. Zhang Y, Dai Y, Zheng T, Ma S. Risk factors of non-Hodgkin lymphoma. Expert Opin Med Diagn 2011;5(6):539-550.

2. Joo YE, Park CH, Lee WS et al. Primary non-Hodgkin's lymphoma of the common bile duct presenting as obstructive jaundice. J Gastroenterol 2004;39: 692.

3. Wang GB, Xu GL, Luo GY, et al. Primary intestinal non-Hodgkin's lymphoma: a clinicopathologic analysis of 81 patients. World J Gastroenterol 2011;17(41):4625-31.

4. Cardona DM, Layne A, Lagoo AS. Lymphomas of the gastro-intestinal tract - pathophysiology, pathology, and differential diagnosis. Indian J Pathol Microbiol 2012;55:1-16.

5. Ghimire P, Wu GY, Zhu L. Primary gastrointestinal lymphoma. World J Gastroenterol 2011;17(6):697-707.

6. Chen Y, Chen Y, Chen S, et al. Primary gastrointestinal lymphoma: a retrospective multicenter clinical study of 415 cases in Chinese province of Guangdong and a systematic review containing 5075 Chinese patients. Medicine (Baltimore) 2015;94(47):e2119.

7. Aledavood A, Nasiri MR, Memar B, et al. Primary gastrointestinal lymphoma. J Res Med Sci 2012;17(5):487-90.

8. Dudgeon DJ, Brower M. Primary chemotherapy for obstructive jaundice caused by intermediate-grade non-Hodgkin lymphoma. Cancer 1993;71(9):2813-6.
9. Hashimoto M, Umekita N, Noda K. Non-Hodgkin lymphoma as a cause of obstructive jaundice with simultaneous extrahepatic portal vein obstruction: a case report. World J Gastroenterol 2008;14(25):4093-5.

10. Yoon MA, Lee JM, Kim SH, et al. Primary biliary lymphoma mimicking cholangiocarcinoma: a characteristic feature of discrepant CT and direct cholangiography findings. J Korean Med Sci 2009;24(5):956-9.

11. Bumbu A, Pasca B, Tit DM, Bungau S, Bumbu G. The effects of soy isoflavones and hormonal replacing therapy on the incidence and evolution of postmenopausal female urinary incontinence. Farmacia 2016;64(3):419-422.

12. Diaconescu D, Pantea Stoian A, Socea LI, et al. Hepatorenal syndrome: a review. Arch Balk Med Union 2018;53(2): 239-245.

13. Mogoanta SS, Costache A, Mutiu G, et al. A nonfunctional neuroendocrine tumor of the pancreas - a case report. Rom J Morphol Embriol 2015; 56(2 Suppl.):511-519.

14. Pallag A, Rosca E, Tit DM, Mutiu G, Bungau SG, Pop OL. Monitoring the effects of treatment in colon cancer cells using immunohistochemical and histoenzymatic techniques. Rom J Morphol Embriol 2015;56(3):1103-1109.

15. Stanimir M, Chiutu LC, Wese S, Milulescu A, Nemes RN, Bratu O. Mullerianosis of the urinary bladder: a rare case report and review of the literature. Rom J Morphol Embriol 2016; 57(Suppl 2): 849-852.

16. Elbanna KY, Al-Shieban S, Azzumeea F. Primary follicular lymphoma of the common bile duct mimicking cholangiocarcinoma. J Clin Imaging Sci 2014;4:72.

17. Diaconu CC, Dragoi CM, Bratu OG, et al. New approaches and perspectives for the pharmacological treatment of arterial hypertension. Farmacia 2018; 66(3):408-415.

18. Diaconu CC, Manea M, Iancu MA, et al. Hyponatremia in patients with heart failure: a prognostic marker. Rev Chim (Bucharest) 2018; 69(5):1071-1074.

19. Diaconu CC, Stanescu AMA, Pantea Stoian A, et al. Hyperkalemia and cardiovascular diseases: new molecules for the treatment. Rev Chim (Bucharest) 2018; 69(6):1367-1370.

20. Ansell SM. Non-Hodgkin lymphoma: diagnosis and treatment. Mayo Clin Proc 2015;90(8):1152-63. 